\title{
O processo de alfabetização com o uso das tecnologias digitais: uma revisão sistemática
}

\author{
Fernanda Nunes Deitos ${ }^{1}$, Rosane Aragón ${ }^{1}$ \\ ${ }^{1}$ Programa de Pós-graduação em Educação - Universidade Federal do Rio Grande do \\ Sul (UFRGS) - CEP 90040-060- Porto Alegre - RS - Brasil \\ \{deitos.fe, rosane.aragon\} @gmail.com
}

\begin{abstract}
This article presents a systematic review of the literature that involves the presence of digital technologies in the literacy process of the early years of elementary school. In order to guide the study, research questions were elaborated addressing its theme, the objective of using technology and the technological resources used. The results show that digital technologies can help in the literacy process in addition to favoring students' motivation and interest, mainly through digital games. Finally, the main challenge is the importance of training teachers for the use of technologies in literacy and the trend towards digital literacy.
\end{abstract}

Resumo: O presente artigo apresenta uma revisão sistemática da literatura que envolve a presença das tecnologias digitais no processo de alfabetização dos anos iniciais do Ensino Fundamental. A fim de nortear o estudo foram elaboradas questões de pesquisa abordando sua temática, o objetivo da utilização da tecnologia e os recursos tecnológicos utilizados. Os resultados apontam que as tecnologias digitais podem auxiliar no processo de alfabetização além de favorecer a motivação e interesse dos alunos, principalmente através de jogos digitais. Por fim, verifica-se, como o principal desafio, a importância da formação de professores para a utilização das tecnologias na alfabetização e a tendência de uma alfabetização digital.

\section{Introdução}

A nossa sociedade contemporânea apresenta-se "em rede", na qual os indivíduos vivem conectados através das informações que se fazem presentes com muita rapidez, sendo necessário saber lidar com elas [CASTELLS, 1999]. Ao mesmo tempo em que a sociedade passa por transformações a educação também deve se reinventar, buscando sustentação em um novo paradigma, no qual o sujeito deve aprender a agir sobre a realidade em que se encontra, por suas situações vivenciadas [BEHAR, 2009].

De acordo com essa reinvenção, a partir das TDIC' s (Tecnologias Digitais da Informação e da Comunicação) apresenta-se um "novo paradigma que modifica as práticas sociais e educacionais" [COLL; MONEREO, 2010, p. 13], possibilitando os sujeitos a desenvolverem competências e habilidades necessárias ao contexto atual, sendocapazes de aprender em rede. Essa aprendizagem em rede possibilita interações e trocas entre os sujeitos, como no caso de professores e alunos [NOVAK, et al., 2014]. Assim é possível que tanto alunos, quanto professores, aprendam e ensinem. 
Compreendendo a relevância de buscar novas práticas para acompanhar as demandas da sociedade e as necessidades de seus alunos, os professores podem se amparar nas ferramentas tecnológicas, para atingir objetivos educacionais. Pois a aprendizagem pode acontecer de diversas formas e em diferentes ambientes, apresentando flexibilidade [JACKSON, 2014]. Sendo assim, acredita-se na busca de recursos tecnológicos para auxiliar no processo de aprendizagem de determinado conteúdo, tornando-o mais motivador.

No processo de ensino muitos são os desafios encontrados pelos professores e o processo de alfabetização, nos anos iniciais, é um deles. A "A alfabetização faceta linguística da aprendizagem inicial da língua escrita - focaliza, basicamente, a conversão da cadeia sonora da fala em escrita" [SOARES, 2016, p. 38], porém, entende-se que, além de adquirir a habilidade de codificar e decodificar o código, é importante que o alunos possam aprender de forma construtiva com diversas práticas de leitura e escrita que façamparte da sua realidade [SOARES, 2004].

Para auxiliar nesse processo são necessários muitos recursos, atividades diferenciadas, jogos, propostas que impulsionem o avanço de nível alfabético, auxiliando na escrita, leitura e oralidade. Dessa forma, além de trabalhar a alfabetização, é necessário propor aos alunos uma verdadeira compreensão dos significados, desenvolvendo sua leitura de mundo, ou seja, o letramento [FERREIRO; TEBEROSKY, 1999]. Pois: "Letraré mais que alfabetizar, é ensinar a ler e escrever dentro de um contexto onde a escrita e aleitura tenham sentido e façam parte da vida do aluno" [SOARES, 2003, p.2].

Nesse contexto, a tecnologia é capaz de aliar os conteúdos escolares ao interesse dos alunos, modificando a forma de ensinar e de aprender (MORÁN, 2009). Contudo, entende-se que essa utilização deve estar interligada as outras atividades, não sendo restrita a momentos específicos e sem sentido. Pensando nisso, este artigo busca analisar apresença desses aspectos nos trabalhos analisados.

\section{Procedimentos Metodológicos}

Esse artigo busca apresentar as pesquisas relacionadas ao tema da alfabetização e o uso das tecnologias digitais neste processo, através de uma revisão sistemática da literatura. Essa é definida como: “[...] uma forma de estudo secundário que utiliza uma metodologiabem definida para identificar, analisar e interpretar todas as evidências disponíveis a respeito de uma questão de pesquisa particular de maneira imparcial e repetível" [KITCHENHAM; CHARTERS, 2007, p.6].

Sendo assim, apresenta-se um tema específico, onde são analisadas as pesquisas relevantes a ele, assim como a seleção de dados presentes em diferentes pesquisas. Tratando-se de uma revisão sistemática da literatura, buscou-se fundamentação em Kitchenham (2004), pois o autor apresenta as diretrizes para esse tipo de pesquisa, de acordo com os seguintes elementos:

i) Questões de pesquisa (QP): (QP1): Qual a temática da pesquisa? (QP2): Qualo objetivo da utilização das tecnologias? (QP3): Quais recursos tecnológicos estão sendo utilizados?

ii) Critérios de inclusão (CI) e critérios de exclusão (CE): (CI1): Pesquisas que abordam a alfabetização nos anos iniciais do Ensino Fundamental; (CI2) Pesquisas 
que envolvem espaços formais de ensino; (CI3): Pesquisas que envolvem recursos tecnológicos; (CE1): Trabalhos completos (CE2): Pesquisas duplicadas, na qual a versão mais antiga é desconsiderada.

iii) Estratégias de busca (EB): (EB1); Definição das bases de dados (EB2): Definição daspalavras-chave; (EB3): Refinamento das pesquisas a partir da leitura dos títulos, palavras-chave e resumos.

\subsection{Questões da pesquisa}

Com o intuito de construir essa revisão sistemática e nortear a pesquisa, foram elencadas as questões que abordam a temática da utilização das tecnologias no processo de alfabetização dos anos iniciais do Ensino Fundamental. Primeiramente foi pensada em uma questão global: De que forma as tecnologias auxiliam no desenvolvimento do processo de alfabetização nos anos iniciais? E, a partir dela as demais: i) Qual a temática da pesquisa? ii) Qual o objetivo de utilização da tecnologia? e iii) Quais os recursos tecnológicos estão sendo utilizados?

\subsection{Critérios de inclusão e exclusão}

Para que as pesquisas fossem apresentadas de acordo com a modalidade de ensino pretendida, como no caso dos anos iniciais do Ensino Fundamental, do conteúdo da alfabetização, abordando o uso das tecnologias, foram utilizados alguns critérios selecionados, sendo eles de inclusão e exclusão. A aplicação dos critérios possibilita que os trabalhos selecionados estejam relacionados às questões de pesquisa [KITCHENHAM;CHATERS, 2007, p.19].

\subsection{Estratégias de busca}

Para dar continuidade à revisão sistemática, foram elencadas as estratégias de busca da presente pesquisa, escolhendo como bases de dados os periódicos da CAPES, a Biblioteca Brasileira de Teses e Dissertações, a Biblioteca Digital Scielo e Base Multidisciplinar de Dados Internacionais Scopus. Para refinar a pesquisa foram definidasas palavras-chave: "alfabetização" AND "tecnologia", no intervalo de tempo dos últimos 5 anos, ou seja, a partir do ano de 2016. No quadro 1 são apresentadas as pesquisas selecionadas de acordo com os critérios de inclusão (CI) e exclusão (CE) aplicados.

\begin{tabular}{|c|c|c|c|c|c|}
\hline & . & 定 & oricana & & \\
\hline \multirow{3}{*}{$\begin{array}{c}\text { Portal de Periódicos da } \\
\text { CAPES }\end{array}$} & \multicolumn{5}{|c|}{344 registros } \\
\hline & CI1 & CI2 & $\mathrm{CI} 3$ & CE1 & CE2 \\
\hline & 19 & 9 & 6 & 3 & 3 \\
\hline \multirow{3}{*}{$\begin{array}{c}\text { Biblioteca Digital Brasileira } \\
\text { de Teses e Dissertações }\end{array}$} & \multicolumn{5}{|c|}{291 registros } \\
\hline & CI1 & $\mathrm{CI} 2$ & CI3 & CE1 & CE2 \\
\hline & 55 & 31 & 6 & 6 & 4 \\
\hline \multirow{2}{*}{ Biblioteca Eletrônica Scielo } & \multicolumn{5}{|c|}{54 registros } \\
\hline & CI1 & $\mathrm{CI} 2$ & $\mathrm{CI} 3$ & CE1 & CE2 \\
\hline
\end{tabular}




\begin{tabular}{|c|c|c|c|c|c|}
\hline & 6 & 4 & 2 & 2 & 2 \\
\hline \multirow{3}{*}{$\begin{array}{c}\text { Base Multidisciplinar de } \\
\text { Dados Internacionais } \\
\text { Scopus }\end{array}$} & \multicolumn{5}{|c|}{234 registros } \\
\hline & CI1 & $\mathrm{CI} 2$ & $\mathrm{CI} 3$ & CE1 & CE2 \\
\hline & 34 & 12 & 12 & 2 & 2 \\
\hline Total & \multicolumn{5}{|c|}{11 pesquisas } \\
\hline
\end{tabular}

Fonte: elaborado pelos autores

Com a leitura dos títulos das pesquisas, palavras-chave e seus resumos, foi possível identificar temas diversos, como, por exemplo, a formação de professores, a inclusão de alunos com deficiência, ambientes não formais de ensino, outras modalidadesde ensino como a educação infantil, o Ensino Fundamental II, o Ensino Médio, profissionalizante, técnico e o Ensino Superior. Além disso, também estavam presentes pesquisas abrangendo outras áreas do conhecimento, como as ciências e a matemática, por exemplo. Todas essas temáticas foram excluídas da seleção com base nos critérios adotados.

\section{Resultados e Discussão}

Após a aplicação dos critérios, foram selecionadas onze pesquisas para serem analisadas de acordo com as questões. As pesquisas selecionadas apresentam quatro dissertações e sete artigos, sendo sete no Brasil, uma na Colômbia, uma na África do Sul e duas nos Estados Unidos, como mostra o Quadro 2.

\section{Quadro 2 - Resultado das Questões de pesquisa}

\begin{tabular}{|c|c|c|c|}
\hline $\begin{array}{l}\text { Autor } \\
\text { Ano } \\
\text { País } \\
\text { Tipo }\end{array}$ & Temática & $\begin{array}{l}\text { Objetivo da } \\
\text { utilização da } \\
\text { tecnologia }\end{array}$ & $\begin{array}{l}\text { Tecnologia } \\
\text { Utilizada }\end{array}$ \\
\hline $\begin{array}{l}\text { [QUEIROZ; } \\
\text { FILHO, 2019] } \\
\text { Brasil } \\
\text { Artigo }\end{array}$ & $\begin{array}{lr}\text { Utilização } & \text { da } \\
\text { Tecnologia } & \text { da } \\
\text { Informação } & \text { e } \\
\text { da Comunicação } \\
\text { (TIC) na ação } \\
\text { didática } \\
\text { pedagógica. }\end{array}$ & $\begin{array}{l}\text { Promover dinamismo } \\
\text { nas aulas, } \\
\text { proporcionando a } \\
\text { aprendizagem da } \\
\text { leitura e da escrita na } \\
\text { perspectiva do } \\
\text { letramento. }\end{array}$ & $\begin{array}{l}\text { Utilização de } \\
\text { notebooks e lousa } \\
\text { digital, na própria } \\
\text { sala de aula, pelas } \\
\text { turmas de } 2^{\circ} \text { ano do } \\
\text { E.F. }\end{array}$ \\
\hline
\end{tabular}




\begin{tabular}{|c|c|c|c|}
\hline $\begin{array}{l}\text { [MOREIRA, et al., } \\
2017 \text { ] } \\
\text { Brasil } \\
\text { Artigo }\end{array}$ & $\begin{array}{l}\text { A dedicação de um } \\
\text { gestor escolar em } \\
\text { promover } \\
\text { utilização a das } \\
\text { tecnologias móveis } \\
\text { para suprir a falta de } \\
\text { recursos, como no } \\
\text { caso de livros } \\
\text { destinados à } \\
\text { alfabetização de um } \\
3^{\circ} \text { ano do E.F. }\end{array}$ & \begin{tabular}{l} 
Utilizar \\
tecnologias as \\
realização de leitura \\
digital devido à \\
escassez de \\
exemplares de \\
livros disponíveis na \\
\multicolumn{2}{c}{ escola. }
\end{tabular} & $\begin{array}{l}\text { Foram utilizados } \\
\text { recursos como } \\
\text { smartfone, blog, } \\
\text { Facebook da escola } \\
\text { e WhatsApp para } \\
\text { compor projeto de } \\
\text { alfabetização. Os } \\
\text { mesmos recursos } \\
\text { foram utilizados } \\
\text { também em casa. }\end{array}$ \\
\hline $\begin{array}{l}\text { [ALVARENGA, et } \\
\text { al., 2018] } \\
\text { Brasil } \\
\text { Artigo }\end{array}$ & $\begin{array}{lr}\text { Utilização } & \text { das } \\
\text { tecnologias } & \text { para } \\
\text { favorecer } & \text { o } \\
\text { processo } & \text { de } \\
\text { alfabetização } & \text { em } \\
\text { uma turma de } 2^{\circ} \text { ano } \\
\text { do E.F. de escola da } \\
\text { rede municipal }\end{array}$ & $\begin{array}{ll}\text { Auxiliar } & \text { no } \\
\text { progresso } & \text { da } \\
\text { alfabetização } & \end{array}$ & $\begin{array}{l}\text { Utilização de jogos } \\
\text { digitais, programas } \\
\text { de desenhos } \\
\text { vetoriais, } \\
\text { processadores de } \\
\text { texto e vídeo. } \\
\text { Manteve-se a } \\
\text { frequência de duas } \\
\text { aulas semanais, } \\
\text { sendo uma em sala } \\
\text { de aula regular, e } \\
\text { outra em } \\
\text { laboratório de } \\
\text { informática, por } \\
\text { cinco meses. }\end{array}$ \\
\hline $\begin{array}{l}\text { [ALEXANDRE, } \\
\text { 2017] } \\
\text { Brasil } \\
\text { Dissertação }\end{array}$ & $\begin{array}{l}\text { Utilização } \\
\text { objetos digitais de } \\
\text { aprendizagem no } \\
\text { processo de } \\
\text { alfabetização } \\
\text { letramento em um } \\
2^{\circ} \text { ano do E.F. }\end{array}$ & $\begin{array}{lr}\text { Auxiliar } & \text { no } \\
\text { processo } & \text { de } \\
\text { alfabetização pois } \\
\text { os alunos } \\
\text { apresentavam } \\
\text { dificuldade com } \\
\text { atividades } \\
\text { tradicionais, como } \\
\text { as cópias do } \\
\text { quadro. }\end{array}$ & $\begin{array}{l}\text { A utilização de } \\
\text { Objetos Digitais de } \\
\text { Aprendizagem } \\
\text { (ODA) e jogos } \\
\text { digitais em turma } \\
\text { do } 2^{\circ} \text { ano do E.F. } \\
\text { A frequência foi } \\
\text { uma vez por } \\
\text { semana, durante as } \\
\text { aulas de } \\
\text { informática por } \\
\text { quatro meses. }\end{array}$ \\
\hline
\end{tabular}




\begin{tabular}{|c|c|c|c|}
\hline $\begin{array}{l}\text { [BLANDINO, } \\
\text { 2016] } \\
\text { Brasil } \\
\text { Dissertação }\end{array}$ & $\begin{array}{lr}\text { Utilização } & \text { de } \\
\text { objetos } & \text { de } \\
\text { aprendizagem como } & \text { apoio aos alunos } \\
\text { que apresentam } \\
\text { dificuldades no } \\
\text { processo } \\
\text { alfabetização de um } \\
1^{\circ} \text { ano do E.F. }\end{array}$ & $\begin{array}{lc}\text { A superação } & \text { das } \\
\text { dificuldades } & \text { de } \\
\text { aprendizagem } & \\
\text { identificadas } & \text { no } \\
\text { processo } & \text { de } \\
\text { alfabetização } & \end{array}$ & $\begin{array}{l}\text { A utilização de } \\
\text { Objetos de } \\
\text { Aprendizagem } \\
\text { (OA) e jogos } \\
\text { digitais durante as } \\
\text { aulas de } \\
\text { informática, de } \\
\text { forma individual, } \\
\text { durante três meses. }\end{array}$ \\
\hline $\begin{array}{l}\text { SANTOS, 2018] } \\
\text { Brasil } \\
\text { Dissertação }\end{array}$ & $\begin{array}{l}\text { A utilização de um } \\
\text { jogo digital como } \\
\text { recurso tecnológico } \\
\text { aplicado com alunos } \\
\text { do } 2^{\circ} \text { ano do E.F. em } \\
\text { processo de } \\
\text { alfabetização }\end{array}$ & $\begin{array}{lr}\text { Jogos } & \text { digitais } \\
\text { serem } & \\
\text { considerados } & \\
\text { recursos } & \text { que } \\
\text { podem } & \text { ser } \\
\text { utilizados } & \text { para } \\
\text { aprendizagem. } & \end{array}$ & $\begin{array}{l}\text { Utilização do jogo } \\
\text { digital GameAlfa, } \\
\text { com alunos do } 2^{\circ} \\
\text { ano do E.F., na sala } \\
\text { de computação, } \\
\text { com a turma } \\
\text { dividida em dois } \\
\text { grupos }\end{array}$ \\
\hline $\begin{array}{l}\text { [SILVA, 2019] } \\
\text { Brasil } \\
\text { Dissertação }\end{array}$ & $\begin{array}{lr}\text { A verificação da } \\
\text { eficácia de jogos } \\
\text { digitais, disponíveis } \\
\text { gratuitamente, no } \\
\text { processo } \\
\text { alfabetização de um } \\
2^{\circ} \text { ano do E.F. }\end{array}$ & $\begin{array}{l}\text { O desenvolvimento } \\
\text { de habilidades } \\
\text { relacionadas à } \\
\text { alfabetização, de } \\
\text { forma a aliar fins } \\
\text { educativos e } \\
\text { instrumentos } \\
\text { divertidos }\end{array}$ & $\begin{array}{l}\text { Por meio de jogos } \\
\text { digitais que } \\
\text { apresentavam } \\
\text { diferentes desafios. } \\
\text { Aplicados através } \\
\text { dos computadores, } \\
\text { na sala de } \\
\text { informática }\end{array}$ \\
\hline $\begin{array}{l}\text { [SOTO } \\
\text { GUTIÉRREZ, } \\
\text { 2019] } \\
\text { Colômbia } \\
\text { Artigo }\end{array}$ & $\begin{array}{l}\text { Utilização } \\
\text { Tecnologia da } \\
\text { Informação da } \\
\text { Comunicação com } \\
\text { alunos do } 1^{\circ} \text { ano do } \\
\text { E.F, para auxiliarem } \\
\text { na alfabetização, } \\
\text { mais } \\
\text { especificamente na } \\
\text { oralidade. }\end{array}$ & $\begin{array}{l}\text { Auxilia nas } \\
\text { dificuldades dos } \\
\text { alunos do } 1^{\circ} \text { ano do } \\
\text { E.F em micro } \\
\text { habilidades como: } \\
\text { expressão oral, } \\
\text { entonação, } \\
\text { pronúncia, entre } \\
\text { outros. }\end{array}$ & $\begin{array}{l}\text { Utilização de Blog, } \\
\text { gravações de voz, } \\
\text { vídeo e jogos } \\
\text { digitais em sala de } \\
\text { aula, presencial, } \\
\text { com auxílio da } \\
\text { professora, e em } \\
\text { casa, com o } \\
\text { acompanhamento } \\
\text { dos pais. }\end{array}$ \\
\hline
\end{tabular}




\begin{tabular}{|c|c|c|c|}
\hline $\begin{array}{l}\text { [MABOE, et al., } \\
2018] \\
\text { África do Sul } \\
\text { Artigo }\end{array}$ & $\begin{array}{l}\text { Utilização de tablets } \\
\text { como } \\
\text { possibilidade para } \\
\text { leitura dos alunos } \\
\text { no E. F. }\end{array}$ & $\begin{array}{lr}\text { Auxiliar no } & \text { fraco } \\
\text { desempenho } & \text { dos } \\
\text { alunos na } & \text { leitura } \\
\text { em } & \text { escolas } \\
\text { primárias. } & \end{array}$ & $\begin{array}{l}\text { Utilização de } \\
\text { audiolivro presente } \\
\text { em tablet, em duas } \\
\text { escolas diferentes, } \\
\text { em sala de aula. }\end{array}$ \\
\hline $\begin{array}{l}\text { [CASTILLO e } \\
\text { WAGNER, 2019] } \\
\text { Estados Unidos } \\
\text { Artigo }\end{array}$ & 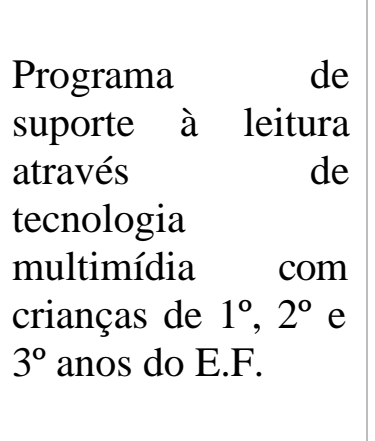 & $\begin{array}{l}\text { Possibilidade de } \\
\text { desenvolvimento } \\
\text { das habilidades de } \\
\text { leitura com } \\
\text { crianças de escolas } \\
\text { rurais, } \\
\text { historicamente } \\
\text { desfavorecidas }\end{array}$ & $\begin{array}{lr}\text { Utilização } & \text { do } \\
\text { Software BFI } & \text { em } \\
\text { laboratório } & \text { de } \\
\text { informática } & \text { das } \\
\text { quatro escolas } & \text { de } \\
\text { aplicação. } & \end{array}$ \\
\hline $\begin{array}{l}\text { [SHAMIR, et al., } \\
\text { 2019] } \\
\text { Estados Unidos } \\
\text { Artigo }\end{array}$ & $\begin{array}{l}\text { Utilização } \\
\text { currículo qe } \\
\text { envolve } \\
\text { alfabetização a partir } \\
\text { do computador }\end{array}$ & $\begin{array}{l}\text { Possibilidade } \\
\text { promover } \\
\text { alfabetização } \\
\text { precoce. }\end{array}$ & $\begin{array}{l}\text { Utilização do } \\
\text { software Waterford } \\
\text { (WEL) ao longo de } \\
\text { um ano escolar com } \\
\text { alunos do } 1^{\circ} \text { ano do } \\
\text { E.F. }\end{array}$ \\
\hline
\end{tabular}

Fonte: elaborado pelos autores

De acordo com as questões selecionadas, foi realizada a análise das pesquisas. Ressalta-se que alguns dos trabalhos selecionados, além de tratarem e terem seu foco na alfabetização, também mencionaram o letramento, visto que, são conceitos que se completam, pois acredita-se no processo de alfabetização através das práticas sociais de leitura e escrita, ou seja, o letramento, reconhecendo esses elementos como indissociáveis [SOARES, 2003].

Os trabalhos selecionados apontam que as tecnologias digitais são capazes de favorecer o interesse dos alunos, enfatizando a utilização através de jogos digitais, por exemplo. Pode-se identificar com as análises que seis pesquisas apresentaram os jogos digitais como recursos tecnológicos, seja através de softwares, objetos de aprendizagem (OA) ou objetos digitais de aprendizagem (ODA). Entende-se que essa tendência acontece, porque o jogo carrega o aspecto lúdico, sendo atrativo e motivador, capaz de engajar os alunos nas propostas das diversas áreas do conhecimento. Sendo assim, não poderia ser diferente no processo de alfabetização. Dessa forma, os professores podem fazer uso dos jogos, já que eles desenvolvem muitas estratégias relevantes para aprimorar o aprendizado [SAVI; ULBRICHT, 2008, p.3].

Na pesquisa de [MOREIRA, et al., 2017] a ideia para utilizar as tecnologias 
digitais surgiu de uma situação cotidiana na qual deveria ser trabalhada a leitura de um livro e havia apenas seis exemplares na escola. Resolveu-se, então, propor o uso dos smartfones em sala de aula, realizando a leitura digital. Também foi possível que essa utilização fosse realizada em casa, com o acompanhamento dos responsáveis, tornando a aprendizagem flexível ao ser construída em tempos e espaços diferentes. Como resultado dessa utilização, os autores destacam a relevância desses recursos, que possibilitam formas diferenciadas de trabalhar com a alfabetização, possibilitando que os alunos apresentem maior autonomia e protagonismo em sua aprendizagem. Nesse sentido, entende-se a importância de práticas que favoreçam as construções dos alunos, que têm papel ativo em seu aprendizado, como traz a concepção construtivista [PIAGET, 1973].

Na pesquisa de [QUEIROZ; FILHO, 2019], a utilização das tecnologias digitais na escola surgiu da necessidade de acompanhar a demanda atual da sociedade, apresentando o conteúdo da alfabetização como um processo que necessita de atividades diferenciadas. Porém houve a dificuldade na falta de recursos como, por exemplo, a internet. Apesar dessa dificuldade, apresentou-se como resultados desse trabalho que o uso das ferramentas tecnológicas foi capaz de motivar os alunos na participação das propostas, auxiliando em sua aprendizagem.

Nos trabalhos de Blandino (2016), Santos (2018) e Silva (2019), a utilização das tecnologias digitais, e, mais especificamente, dos jogos digitais, surgiu do desafio que o processo de alfabetização representa, e, pensando nisso, entenderam a importância de buscar propostas lúdicas e capazes de abordar esse conhecimento. Como resultado das pesquisas, os alunos motivaram-se e progrediram de nível alfabético, desenvolvendo sua consciência fonológica, sua oralidade e sua leitura, sendo capazes de refletir sobre a sua realidade. Nessa perspectiva comprende-se a importância de práticas que envolvam a experiência dos alunos, de seu contexto e das trocas com os demais [FREIRE, 2006].

Nos trabalhos de [MABOE, et al., 2018] e [CASTILLO e WAGNER, 2019], os sujeitos da pesquisa são alunos da África do Sul. Nesse contexto, identificou-se uma preocupação com o desempenho dos alunos em relação à leitura e, por esse motivo, buscou-se a utilização da tecnologia digital com o uso do tablet e software, respectivamente. Com isso, apresentou-se como resultados desses trabalhos um aprimoramento e uma compreensão na leitura, assim como, o desenvolvimento da consciência fonológica e o aumento no vocabulário dos alunos, que puderam utilizar diferentes recursos como portadores de texto.

Um aspecto interesse percebido nas pesquisas de [SOTO e GUTIÉRREZ, 2019] e [SHAMIR, et al., 2019], foi a preocupação com a alfabetização precoce. Esse aspecto foi a motivação para utilização das tecnologias digitais, que apresentaram como resultado, respectivamente, a capacidade de autorregulação da aprendizagem e desenvolvimento das habilidades relacionadas à alfabetização. Demonstrando que mesmo os alunos mais novos já estão adaptados à tecnologia.

A partir das análises das pesquisas identifica-se que os trabalhos internacionais selecionados centraram-se em leitura, consciência fonológica e 
oralidade. Ademais, os trabalhos, como é o caso de [SOTO e GUTIÉRREZ, 2019] e [MABOE, et al., 2018], demonstram aliar ao processo de alfabetização da língua nativa a aprendizagem da leitura, escrita e oralidade de uma segunda língua, desenvolvendo uma alfabetização precoce, por acreditarem que, quanto mais cedo, maior facilidade para aprender. E, neste âmbito, as tecnologias digitais favoreceram também nesse processo de aquisição da segunda língua, nessas pesquisas.

No trabalho de Alexandre (2017), a utilização da tecnologia digital surgiu do fato de a escola apresentar os recursos, como computadores, em sala de informática, mas os professores apresentarem dificuldades em sua utilização. Porém, por entenderem a importância desses recursos, buscaram apresentar (ODA's) e jogos digitais, resultando em maior autonomia dos alunos, ao utilizarem esse recurso a que já estão habituados, e progresso no nível alfabético. Pois, entende-se que atividades lúdicas como os jogos são capazes são capazes de influenciar no desenvolvimento da criança, aprofundamento, entre outros, o desenvolvimento da linguagem [VYGOTSKY, 1998].

Por último, a pesquisa de [ALVARENGA, et al., 2018], motivou a utilização dos recursos tecnológicos a partir da percepção do progresso lento que os alunos apresentavam, apesar de serem propostas atividades instigantes. Assim, foi possível que os alunos se interessassem na proposta avançando em seu nível alfabético. Nesse contexto percebe-se a importância do professor realizar uma avaliação atenta do progresso dos alunos, pensando em estratégias para facilitar a aprendizagem e guiando esse caminho [COLL, 2004].

Analisando os trabalhos selecionados, entende-se que há uma preocupação sobreo conhecimento que o professor deve ter para utilizar as tecnologias digitais no contexto escolar. Pois acredita-se que a tecnologia não deve ser apenas concebida como um auxílio para aprendizagem, mas como "elemento que funda e organiza as novas relações e formas depensar" [ALONSO, et al., 2014, p.162]. Dessa forma, é necessária uma utilização das tecnologias com consciência [LÉVY, 2005].

Os trabalhos analisados apontam que os professores até podem aprender a utilização de um recurso tecnológico, mas apresentam dificuldade na inserção em seus planejamentos e, sendo assim, acabam tornando este um momento isolado. Dessa forma, muitos professores se sentem receosos por realmente não estarem preparados, uma vez que, em suas formações, não tiveram o conhecimento necessário sobre o uso das tecnologias digitais. Além disso, não se sentem preparados para lidar com seus alunos que apresentam habilidades digitais, e, assim, acabam escolhendo atividades que estão acostumados a propor [PRENSKY, 2001]. Dessa forma, entende-se que, ainda hoje, esse representa um desafio para os professores.

Com as análises ralizadas foram elencados os dados presentes nas pesquisas, apresentados no quadro 3 .

\section{Quadro 3: Dados das pesquisas analisadas}

\begin{tabular}{|l|}
\hline Utilização de jogos digitais \\
\hline $\begin{array}{l}\text { Utilização das tecnologias digitais em } \\
\text { tempos eespaços flexíveis }\end{array}$ \\
\hline
\end{tabular}




\begin{tabular}{|l|}
\hline $\begin{array}{l}\text { Leitura digital a partir de smartphone e } \\
\text { tablet }\end{array}$ \\
\hline Protagonismo e autonomia do aluno \\
\hline $\begin{array}{l}\text { Motivação na aprendizagem da } \\
\text { alfabetização }\end{array}$ \\
\hline Alfabetização precoce \\
\hline
\end{tabular}

Fonte: elaborado pelos autores

Entende-se que vivemos em um cenário em que os alunos, mesmo os mais novos, já estão habituados às tecnologias. Sendo assim, o professor deve utilizar esse recurso, reconhecendo que a aprendizagem se faz possivel em tempos e espaços flexíveis, como está sendo vivenciado no cenário atual de ensino remoto. Essa aprendizagem com as tecnologias digitais traz protagonismo aos alunos, que se sentem mais motivados em sua aprendizagem, por exemplo, ao realizarem suas atividades, como a leitura digital, através do seu próprio celular e tablet, em suas próprias casas.

Pensando nesse conhecimento dos alunos percebe-se que há a tendência de uma alfabetização precoce, onde possam ser utilizadas as tecnologias digitais, como por exemplo, os jogos digitais, que são recursos em que o aluno aprende, muitas vezes sem perceber, pois está se divertindo.

Pensando nisso, torna-se relevante que o professor busque compreender a alfabetização e o letramento digital, a fim de contemplar também o ensino remoto e as novas possibilidades de ensino e de aprendizagem.

\section{Considerações finais e trabalhos futuros}

Como principal resultado da análise dos trabalhos selecionados, verifica-se que as tecnologias digitais usadas no processo de alfabetização favoreceram a aprendizagem, engajando os alunos nas propostas pedagógicas. Porém, ainda há uma preocupação, por parte dos professores, com a qualidade dessas propostas, pois, acredita-se na necessidade de uma formação que possibilite a compreensão sobre a forma de inserção delas, para que não sejam apresentadas fora de contexto, como uma atividade que está isolada das restantes.

Com as análises realizadas, entende-se a importância das tecnologias digitais na construção do conhecimento. Possibilitando o desenvolvimento da alfabetização com diferentes estratégias e recursos como, por exemplo, a realização de leitura através de tablet e celular, favorecendo uma alfabetização precoce a esses sujeitos que estão inseridos no contexto digital.

Ao refletir sobre trabalhos futuros, envolvendo a presença da tecnologia digital no processo de alfabetização, entende-se a importância de propostas que estejam inseridas no planejamento do professor, apresentando objetivos a serem alcançados e que estejam relacionadas com as demais atividades utilizadas no processo de alfabetização, para que sejam um elemento que compõe o processo de aprendizagem, pensando no atual cenário e contemplando também o ensino remoto a partir de uma alfabetização digital. 


\section{REFERÊNCIAS}

Alexandre, M. dos R. (2017) "Um estudo sobre objetos digitais de aprendizagem no processo de alfabetização e letramento". Dissertação de mestrado, Bauru.

Alonso, K. M; Aragon, R.; Silva, D. G.; Bicca, S. (2014)" Aprender e ensinar em tempos de cultura digital". Revista Em Rede, v. 1, p. 152-168.

Alvarenga, J. C. da S.; Araújo, M. M.; Santos, N.N. dos. (2018)

"Nos/dos/com cotidianos da alfabetização de nativos digitais". Revista Contemporânea de Educação, v. 13, n. 26, maio/ago.

Behar, P. A. (org.). (2009). "Modelos Pedagógicos em Educação a Distância". Porto Alegre: Artmed,

Blandino, J. F. (2016). "O uso de objetos de aprendizagem como recurso de apoio às dificuldades na alfabetização" São Paulo, Araraquara, Dissertação de mestrado.

Castells, M. (1999). “A sociedade em rede”. São Paulo: Paz e Terra, v.1.

Castillo, N. M; Wagner, D. A.(2019) "Apoio à leitura no primeiro grau na zona rural da África do Sul: Uma abordagem de tecnologia centrada na linguagem". International Review of Education65:389-408.

Coll, C.; Monereo, C. (2010) "Psicologia da Educação Virtual: aprender e ensinar com as tecnologias da informação e da comunicação". Trad. Naila Freitas. Porto Alegre: Artmed.

Coll, C. Palacios, J. e Marchesi, A. (2004) "Desenvolvimento psicológico e educação" Editora grupo A. Porto Alegre.

Ferreiro, E. e Teberosky, A. (1999) “A psicogênese da língua escrita”. Porto Alegre: Artmed.

Freire, P. (2006) "A importância do ato de ler: em três artigos que se completam" 47. Ed. São Paulo: Cortez.

Jackson, N. L. (2014) “Lifewide Learning: History of an idea” In: Jackson, N. L e Cooper, B.(Orgs) Lifewide Learning, Education \& Personal Devlopment.

Kitchenham, B. (2004) "Procedures for Performing Systematic Reviews Technical Report “ Departament of Computer Science Keele University, Keele.

Kitchenham, B. e Charters, S. (2007). Guidelines for performing systematic literature reviews in software engineering. Technical Report EBSE 2007-001, Keele Universityand Durham University Joint Report.

Lévy, P. (2005) “Cibercultura” São Paulo: Ed.34.

Maboe, E, Smith, C. Ga; Banoobhai, Mumthaz; Makgatho, Moses. (2018) "Implementando tablets para ensinar leitura na $5^{\text {a }}$ série" Leitura e escrita vol.9 n.1 Cidade do Cabo.

Morán, J. M. (2009) "Novas tecnologias e mediação pedagógica”. In: Morán, J. M.; MASETTO, M. T.; BEHRENS, M. A Mudar a forma de ensinar e de aprender. 16. ed. Campinas, SP: Papirus, p. 57-72. 
Moreira, V. A. da; Bolsoni, M. V. da S; Balbinot, V. de C. da S; Santos, C.A. S. dos; Salazar, L. B. (2017) "Gestor escolar e as tecnologias móveis na alfabetização" Revista Geminis, v. 8, n. 1.

Novak, S.; Aragón, R.; Ziede, M.; Menezes, C. (2014) “Aprendizagem em rede na Educação a Distância: Práticas e Reflexões” Porto Alegre: Evangraf.

Piaget, J. (1973) “O nascimento da inteligência na criança” Editora Crítica: São Paulo.

Prensky, M. (2001) “Digital natives, digital immigrants” Wagon Lane: MCB University.

Queiroz, M. G; Filho, S. B. (2019) “A Tecnologia como ferramenta didática no processo de alfabetização de crianças"

Santos, A. Q. dos. (2018) "Gamealfa: jogo digital como recurso tecnológico para alunos em processo de alfabetização do segundo ano do ensino fundamental" Amazonas, Dissertação de mestrado.

Savi, R; Ulbricht, V. R. (2008) "Jogos digitais educacionais: benefícios e desafios" RENOTE, v. 6, n. 1.

Shamir, H; Yoder, E.; Pocklinton, D; Feehan, K. (2001) "Tecnologia que melhora as habilidades de alfabetização para todos os alunos: descobertas de três distritos" International Journal of Information and Education Technology, Vol. 9, No. 4, April.

Silva, A. R. da. (2019) "Jogos digitais no cilco de alfabetização: um caminho no processo de alfabetizar letrando" Rio Grande do Norte, Dissertação de mestrado.

Soares, M. (2003) “Letramento e alfabetização: as muitas facetas” Universidade Federal deMinas Gerais, Centro de Alfabetização, Leitura e Escrita.

Soares, M. (2004) "Alfabetização e Letramento: Caminhos e descaminhos" Revista Pedagógica Artmed.

Soto, L. D. A; Gutiérrez, Y. A. G. (2019) “Alfabetização digital e hábitos básicos de autorregulação na aprendizagem de inglês como língua estrangeira na primeira infância" Folios, 49, 177-196.

Vygotsky, L. (1998) “Aprendizagem, desenvolvimento e linguagem” 2. Ed. São Paulo: Icon. 